\title{
Development of a Catalyst for Flue Gas Purification from Carbon Monoxide of Multi-Chamber Furnaces for Baking Electrode Blanks
}

\author{
Olena Ivanenko ${ }^{1 *}$, Andrii Trypolskyi ${ }^{2}$, Nikolai Gomelya ${ }^{1}$, Anton Karvatskii', \\ Andrii Vahin ${ }^{3}$, Olga Didenko², Viktoria Konovalova ${ }^{4}$, Peter Strizhak ${ }^{2}$ \\ 1 Faculty of Chemical Engineering, Igor Sikorsky Kyiv Polytechnic Institute, Prosp. Peremohy, 37/4, 03056 Kyiv, \\ Ukraine \\ 2 L.V. Pisarzhevskii Institute of Physical Chemistry of the National Academy of Sciences of Ukraine, Prosp. of \\ Science, 31, 03028 Kyiv, Ukraine \\ 3 Private Joint Stock Company «Ukrainian Graphite», Pivnichne shose str., 20, 69600 Zaporizhzhia, Ukraine \\ ${ }^{4}$ National University of Kyiv-Mohyla Academy, Skovorody Street, 2, 04070 Kyiv, Ukraine \\ * Corresponding author's e-mail: olenka.vasaynovich@gmail.com
}

\begin{abstract}
The catalysts based on natural zeolite-clinoptilolite of Sokyrnytsia deposit modified with oxides of $\mathrm{Mn}^{4+}, \mathrm{Fe}^{2+}$, $\mathrm{Fe}^{3+}, \mathrm{Cu}^{2+}, \mathrm{Cr}^{3+}$ were synthesized. It was determined that $100 \%$ conversion of carbon monoxide was achieved at a temperature of $390^{\circ} \mathrm{C}$ when using the copper-manganese-oxide catalyst $\left(30 \% \mathrm{CuO}+70 \% \mathrm{MnO}_{2}\right)$. It was shown that although the use of the manganese-oxide catalyst provided $92.8 \%$ of $\mathrm{CO}$ conversion degree, this catalyst had the most advantages for application compared to the other studied solids. The structural parameters of the manganese-oxide catalyst were determined using XRD, SEM, and nitrogen adsorption. The composition of the main elements of the catalyst samples was determined by micro-X-ray spectral analysis. It was shown that using the catalyst containers in chambers heated by flue gases in the fire channels of a multi-chamber furnace for baking of electrode blanks can be one of the constructive solutions to the problem of flue gas purification from carbon monoxide. The environmental safety of the copper-manganese-oxide catalyst application for the treatment of the flue gases of electrode production is justified by obtaining a catalyst from spent sorbents for purification of the manganese-containing natural water and its non-toxicity in the case of burial or storage in landfills.
\end{abstract}

Keywords: carbon monoxide, flue gases, purification, catalyst, oxidation, conversion, multi-chamber furnaces

\section{INTRODUCTION}

As a result of anthropogenic activity, $350-600$ million tons of toxic carbon monoxide, out of which $56-62 \%$ is accounted for by vehicles, are annually formed in the air of industrial centers, and the content of carbon monoxide in exhaust gases can reach 12\% [Kursov, 2015]. Although $\mathrm{CO}$ has high toxicity and high emissions into the atmosphere are observed, until recently, effective treatment methods of industrial waste gases from this dangerous component have not been introduced either in our country or abroad. The only exception involves the road transport gas emissions, which are purified by the $\mathrm{CO}$ catalytic oxidation method [Patel et al., 2019]. This is the most effective method of combating carbon monoxide. However, the use of equipment with a catalyst containing mainly precious metals is very expensive, has a low throughput, and therefore cannot meet the needs of large companies.

In Ukraine, the carbon monoxide emissions amount to about 1.7611 million tons per year (in 2018), which corresponds to $45.81 \%$ of pollutants emissions, excluding carbon dioxide, from stationary sources and road transport. The release of significant amounts of toxic $\mathrm{CO}$ into the atmosphere is a serious problem that must be addressed at the level of industrial production [Statistical Yearbook "Environment of Ukraine 2018", 2019]. 
The Zaporizhia region, especially the city of Zaporizhia, with a high concentration of mining and processing enterprises, belongs to the industrially developed areas of Ukraine with a significant technogenic impact. It should be noted that the increased man-made load on the air in this region is formed not only by a considerable number of environmentally hazardous objects of critical infrastructure of Ukraine but also due to the inefficient operation of gas treatment facilities in the region [Ivanenko O., 2020]. In particular, the accumulation of industrial enterprises in Zaporizhia with a predominance of heavy industry, which includes PrJSC "Ukrgrafit", led to the formation of a territory of significant man-made impact with the load on the environment of Ukraine due to the carbon monoxide emissions of about 7\%. Given that the emissions of PrJSC "Ukrgrafit" contain $41.97 \%$ of carbon monoxide [Environmental passport of Zaporizhzhia region for 2018, 2019], it is necessary to develop the measures to reduce the carbon monoxide emissions with the flue gases formed mainly in electrode production kilns to improve the environmental safety of the company and Ukraine.

In the world practice of electrode production, multi-chamber closed ring furnaces, such as the Riedhammer furnace, are the most widespread devices for the baking process [Riedhammer, 2006]. During their operation, carbon monoxide is formed due to the oxidation of carbon materials of electrode blanks and filling [Panov et al., 2020]. Today, the maximum permissible emission of CO in Ukraine is $250 \mathrm{mg} / \mathrm{m}^{3}$ [The Standards of Maximum Permissible Emissions of Polluting Substances from Stationary Sources, 2006], while at PrJSC "Ukrgrafit" the emissions exceed the standard in furnaces № 9, where the actual concentration reaches $998.3 \mathrm{mg} / \mathrm{m}^{3}$, and in furnaces № 10, with an actual concentration of $1750 \mathrm{mg} / \mathrm{m}^{3}$. Thus, the need to transform the process into a more environmentally friendly one requires the search for innovative technical solutions to reduce the formation of $\mathrm{CO}$ at electrodes baking.

The proposed steps to reduce the intensity of gas emissions during the baking of electrode blanks include determining the modernization of process regulations [Karvatskii et al., 2011], the use of heat exchanger-utilizer for local CO combustion [Karvatskii et al., 2013], the use of intermetallics NiAl, $\mathrm{NiAl}_{3}, \mathrm{Ni}_{2} \mathrm{Al}_{3}$ in catalytic reactors for CO disposal [Belokon et al., 2016]. The implementation of these technical solutions at the company, except for the modernized regulations, is limited or impossible due to significant capital expenditures for the reconstruction or modernization of production. Therefore, it is still important to address the harmful effects of carbon monoxide emissions into the atmosphere and to develop the measures to reduce its negative impact on the environment as well as neighboring housing and public buildings in a cost-effective way without significant re-equipment of production.

Placing catalyst containers in chambers heated by flue gases in the fire channels of multichamber furnace [Riedhammer, 2006] for baking of electrode blanks can be one of the constructive solutions to the problem of flue gas purification from carbon monoxide. Thus, the aim of the research is to develop the catalysts for CO oxidation to solve an important scientific and applied problem of man-made pollution by electrodes production plants. The necessary conditions for the choice of catalyst are cheapness, availability, the prevalence in Ukraine, high performance and multi-functionality in terms of environmental catalysis, providing a fundamentally waste-free environmentally friendly technology.

The use of zeolite of the Sokyrnytsia deposit for purification of natural and wastewater from the $\mathrm{Mn}^{2+}, \mathrm{Fe}^{2+}, \mathrm{Fe}^{3+}, \mathrm{Cu}^{2+}, \mathrm{Cr}^{3+}$ ions is widely known in Ukraine and abroad [Basaraba et al., 2014; Zasidko et al., 2017; Malovanyy M. et al., 2010]. Due to a strictly defined pore size, zeolites also adsorb $\mathrm{N}_{2}, \mathrm{CO}_{2}, \mathrm{SO}_{2}, \mathrm{H}_{2} \mathrm{~S}, \mathrm{Cl}_{2}, \mathrm{NH}_{3}$ from gaseous and liquid systems [Yanovska et al., 2008]. Regarding the choice of catalyst material, taking into account the cheapness and prevalence, the Sokyrnytsia deposit of natural zeolites in the Transcarpathian region of Ukraine is one of the largest in the world. Its reserves are explored and approved in the amount of 126.1 million tons on an area of 161 hectares. The mineral composition of the zeolite rock of the deposit is represented by clinoptilolite, which is based on an open tetrahedral frame that has a negative charge and a system of pores (channels), determined by the silica content. It provides significant sorption capacity towards the positively charged ions. In clinoptilolite, the $\mathrm{Si} / \mathrm{Al}$ ratio should be 4.5-5.5 [Malovanyy et al., 2010; Grechanovskaya, 2010]. The use of these natural materials to solve the environmental problems is topical, given the interest of world science in the adsorption properties of clinoptilolites from Sokyrnytsia deposit and the possibility 
of their practical application on an industrial scale [Korablev et al., 2017].

The application of zeolites in catalysis has been known for a long time due to the good combination of structural adsorption and physicochemical properties of the combination with metal oxides, which are freely incorporated into the pores of zeolites [Inglezakis et al., 2012]. Zeolite-clinoptilolite, modified by transition metal oxides, in particular $\mathrm{MnO}_{2}$, is of considerable interest in the sorption-catalytic processes in aqueous solutions [Korablev et al., 2017; Tarasevich et al., 2012]. In addition, the papers [Panov et al., 2019; Choi et al., 2016] showed the possibility of using $\mathrm{MnO}_{2}$ as a catalyst for the $\mathrm{CO}$ oxidation. Regarding the use of natural zeolites of the Sokyrnytsia deposit of Ukraine for the oxidation of carbon monoxide, it was proposed to use an expensive $\mathrm{Pd}-\mathrm{Cu}$ catalyst settled on acid-thermally modified clinoptilolite of the Sokyrnytsia deposit [Rakitskaya et al., 2011]. Other works focus on the modification of the clinoptilolite of the Sokyrnytsia deposit with manganese oxide (IV) by fixing a divalent manganese ion in the clinoptilolite matrix and its subsequent oxidation by permanganate ion [Korablev et al., 2017].

It is also known that hopkalites, which typically contain $60 \% \mathrm{MnO}_{2}, 40 \% \mathrm{CuO}$ or $70 \%$ $\mathrm{MnO}_{2}, 30 \% \mathrm{CuO}$ are widely used for $\mathrm{CO}$ oxidation [Golodets, 1983]. Regarding the practical application of hopkalite catalyst under wet conditions, which characterizes the processes of baking of electrode blanks [Panov et al., 2012], its undesirable deactivation can be avoided by preparing hopkalite by pyrolysis, but the application of this method on an industrial scale requires additional costs [Biemelt et al., 2016]. Other studies showed that a prerequisite for the effective use of manganese and copper-based catalysts is the impossibility of using sodium compounds as a precipitator, as $\mathrm{Na}^{+}$acts as a catalytic poison [Mirzaei et al., 2003]. Although the aging of the precipitates increases the catalytic activity due to the reduction of the surface sodium concentration on the oxide precipitates, it is preferable to use other precipitators, such as ammonia solution, which is easily desorbed from the solution into the gas phase.

Using $\mathrm{Cr}_{2} \mathrm{O}_{3}$ as a promising material for environmentally benign catalysis [Golodets, 1983] can be based on the utilization of the spent chromate-containing electrolytes by means of the reagent method with the reduction of $\mathrm{Cr}^{6+}$ to $\mathrm{Cr}^{3+}$ by sodium sulfite or bisulfite and precipitation of $\mathrm{Cr}^{3+}$ by alkaline reagent [Radovenchik et al., 2020. However, it should be noted that the use of sodium sulfite or bisulfite to reduce $\mathrm{Cr}^{6+}$ to $\mathrm{Cr}^{3+}$ and an alkaline reagent containing sodium ions to precipitate $\mathrm{Cr}^{3+}$ does not always lead to the obtaining of $\mathrm{Cr}_{2} \mathrm{O}_{3}$ sediment with good catalytic properties due to the presence of $\mathrm{Na}^{+}$in the catalyst composition. The use of ferrite sludge as a valuable raw material for the $\mathrm{CO}$ oxidation catalysts also has good potential for environmental use [Lou et al., 2006]. It is known that the ferric materials based on magnetite, copper ferrite, and chromium ferrite can be easily obtained in the extraction processes of heavy metal ions from etching solutions and spent electrolytes of galvanic coatings in metallurgical industries [Radovenchik et al., 2020].

Therefore, the development of a catalyst based on natural zeolite-clinoptilolite Sokyrnytsia deposit, modified by $\mathrm{Mn}^{4+}, \mathrm{Fe}^{2+}, \mathrm{Fe}^{3+}, \mathrm{Cu}^{2+}, \mathrm{Cr}^{3+}$ oxides, is a promising area. It allows obtaining new effective and cheap materials from both natural materials and spent sorbents after the treatment of natural and wastewater with metal ions already adsorbed on their surface. The polyfunctionality of an obtained catalyst will be improved even in the case of a modification of its surface with ferric material during the treatment of galvanic effluents. In addition, the spent catalyst in the case of the landfill is non-toxic, with limited biodegradability [Lou et al., 2006] and can be used without pre-treatment in the production technologies for other materials, for example, as a component of a hard surface for roads construction and as an additive for production of building materials [Yanovska et al., 2008; Rakhimova et al., 2007; Vatin et al., 2013].

\section{MATERIALS AND METHODS}

The zeolite rock originated from the Sokyrnytsia deposit of the Zakarpattia region produced by "Zakarpattia Zeolite Plant" LLC with the particle size of 3-5-8 mm of PCO grade type A with target fraction content $85 \%$ according to technical conditions TU U 19.5-00292540.001-2001 "Rubble and sand from the natural zeolite. Sokyrnytsia deposit". According to the data provided by the company, the batch of zeolite $(\mathrm{Na}, \mathrm{K})_{6}\left[\left(\mathrm{Al}_{6} \mathrm{Si}_{30}\right)\right.$ $\mathrm{O}_{72}$ ] $20 \mathrm{H}_{2} \mathrm{O}$ [Grechanovskaya, 2010] is made of zeolitized tuffs of clinoptilolite type with clinoptilolite content about $83 \%$ with the possible 
presence of admixtures of montmorillonite, feldspar, volcanic glass. The density is $2.37 \mathrm{~kg} / \mathrm{m}^{3}$, cation exchange capacity $-1.5 \mathrm{mg}-\mathrm{eq} / \mathrm{g}$, thermal resistance - up to $700^{\circ} \mathrm{C}$, mechanical compressive strength - up to $150 \mathrm{~kg} / \mathrm{cm}^{2}$, mechanical abrasive wear resistance - not more than $4 \%$, mechanical grinding strength - not more than $0.5 \%$, the total specific activity of natural radionuclides -144.5 $\mathrm{Bq} / \mathrm{kg}$. The chemical composition of zeolite rock (wt.\%): $\mathrm{SiO}_{2}-71.5 ; \mathrm{Al}_{2} \mathrm{O}_{3}-13.1 ; \mathrm{Fe}_{2} \mathrm{O}_{3}-0.9$; $\mathrm{TiO}_{2}-0.5 ; \mathrm{CaO}-3.44 ; \mathrm{MgO}-0.68 ; \mathrm{K}_{2} \mathrm{O}+\mathrm{Na}_{2} \mathrm{O}$ $-3.03 ; \mathrm{P}_{2} \mathrm{O}_{5}-0.014, \mathrm{Cu}-0.02 ; \mathrm{F}-0.025 ; \mathrm{Pb}-$ 0.002 ; As -0.0015 .

In order to obtain a modified zeolite, $150 \mathrm{~g}$ of dried solid was placed in $150 \mathrm{~cm}^{3}$ of a solution containing one of the following ions $\mathrm{Mn}^{2+}$, $\mathrm{Mn}^{6+}, \mathrm{Fe}^{2+}, \mathrm{Cu}^{2+}, \mathrm{Cr}^{3+}$ according to the following methods.

Synthesis of the manganese-oxide catalyst [Tarasevich et al., 2013; Mitzi, 2009]: a sample of zeolite was treated with $0.475 \mathrm{M} \mathrm{MnCl}_{2}$ solution for $1 \mathrm{~h}$, then $\mathrm{MnO}_{2}$ was precipitated on the zeolite using $0.316 \mathrm{M} \mathrm{KMnO}_{4}$ solution and kept for 24 hours. The modified zeolite was then separated from the aqueous phase by decantation, washed, and air-dried to constant weight.

Synthesis of the copper-manganese-oxide catalyst $\left(30 \% \mathbf{C u O}+\mathbf{7 0} \% \mathrm{MnO}_{2}\right)$ [Mitzi, 2009]: a sample of zeolite was treated with 0.333 $\mathrm{M} \mathrm{MnCl}{ }_{2}$ solution for $1 \mathrm{~h}$, then $\mathrm{MnO}_{2}$ was precipitated by adding $0.221 \mathrm{M} \mathrm{KMnO}_{4}$ solution and kept for 24 hours. Afterwards, the manganese oxide-modified zeolite was separated from the aqueous phase by decantation, washed and treated with $0.094 \mathrm{M} \mathrm{CuSO}_{4}$ solution for $1 \mathrm{~h}$, then $\mathrm{Cu}(\mathrm{OH})_{2}$ was precipitated on the zeolite using $25 \% \mathrm{NH}_{4} \mathrm{OH}$ solution and kept for 24 hours. The modified zeolite was then separated from the aqueous phase by decantation, washed, and airdried to constant weight.

Synthesis of the copper-manganese-oxide catalyst $\left(40 \% \mathrm{CuO}+\mathbf{6 0} \% \mathrm{MnO}_{2}\right)$ [Mitzi, 2009]: a sample of zeolite was treated with 0.285 $\mathrm{M} \mathrm{MnCl}_{2}$ solution for $1 \mathrm{~h}$, then $\mathrm{MnO}_{2}$ was precipitated by adding $0.190 \mathrm{M} \mathrm{KMnO}_{4}$ solution and kept for 24 hours. The manganese oxide-modified zeolite was then separated from the aqueous phase by decantation, washed and treated with $0.125 \mathrm{M}$ $\mathrm{CuSO}_{4}$ solution for $1 \mathrm{~h}$, then $\mathrm{Cu}(\mathrm{OH})_{2}$ was precipitated on the zeolite using $25 \% \mathrm{NH}_{4} \mathrm{OH}$ solution and kept for 24 hours. The modified zeolite was then separated from the aqueous phase by decantation, washed, and air-dried to constant weight.
Synthesis of the ferrite catalyst $\left(\mathrm{Fe}^{2+}: \mathrm{Fe}^{3+}=1: 2\right)$ [Radovenchik et al., 2020]: a sample of zeolite was treated with a mixture of $0.119 \mathrm{M} \mathrm{FeSO}_{4}$ and $0.238 \mathrm{M} \mathrm{FeCl}_{3}$ solutions for $1 \mathrm{~h}$, then magnetite $\mathrm{Fe}_{3} \mathrm{O}_{4}$ was precipitated on the zeolite using $25 \% \mathrm{NH}_{4} \mathrm{OH}$ solution and kept for 24 hours. The modified zeolite was then separated from the aqueous phase by decantation, washed, and air-dried to constant weight.

Synthesis of the copper-ferrite catalyst $\left(\mathrm{Cu}^{2+}: \mathbf{F e}^{2+}=\mathbf{1 : 3 . 5 3}\right)$ [Radovenchik et al., 2020]: a sample of zeolite was treated with a mixture of $0.069 \mathrm{M} \mathrm{CuSO}_{4}$ and $0.278 \mathrm{M} \mathrm{FeSO}_{4}$ solutions for $1 \mathrm{~h}$, then copper ferrite $\mathrm{CuFe}\left(\mathrm{FeO}_{2}\right)_{3}$ was precipitated on the zeolite using $25 \% \mathrm{NH}_{4} \mathrm{OH}$ solution and kept for 24 hours. The modified zeolite was then separated from the aqueous phase by decantation, washed, and air-dried to constant weight.

Synthesis of the chromium-ferrite catalyst $\left(\mathbf{C r}^{6+}: \mathbf{F e}^{2+}=\mathbf{1 : 1 5}\right)$ [Radovenchik et al., 2020]: a sample of zeolite was treated with a mixture of $0.028 \mathrm{M} \mathrm{K}_{2} \mathrm{Cr}_{2} \mathrm{O}_{7}$ and $0.332 \mathrm{M} \mathrm{FeSO}_{4}$ solutions for $1 \mathrm{~h}$, then chromium ferrite was precipitated on the zeolite using $25 \% \mathrm{NH}_{4} \mathrm{OH}$ solution and kept for 24 hours. The modified zeolite was then separated from the aqueous phase by decantation and air-dried to constant weight.

Synthesis of the chromium-oxide catalyst [Radovenchik et al., 2020]: a sample of zeolite was treated with $0.385 \mathrm{M} \mathrm{Cr}_{2}\left(\mathrm{SO}_{4}\right)_{3}$ solution for $1 \mathrm{~h}$, then $\mathrm{Cr}(\mathrm{OH})_{3}$ was precipitated on the zeolite using $25 \% \mathrm{NH}_{4} \mathrm{OH}$ solution and kept for 24 hours. The modified zeolite was then separated from the aqueous phase by decantation, washed, and air-dried to constant weight.

Study of the CO oxidation: the experimental setup (Fig. 1) includes a thermal chamber 8 , consisting of a metal tube made of stainless steel 9 and a ceramic tube 10 with a heating element 11 , in which the set temperature was maintained using thermocouples 12 and a thermal relay 13 . A sample of the catalyst with a grain size $3-5-8 \mathrm{~mm}$ in a cylindrical container 13 was placed in a metal tube 9 . The dimensions of the container were: height $160 \mathrm{~mm}$, diameter $60 \mathrm{~mm}$. The container with a height of catalyst load $50 \mathrm{~mm}$ was placed into tube 9 to prevent the passing of the gas mixture by the catalyst. The volumetric gas flow rate was varied in the range of $1-5 \mathrm{dm}^{3} / \mathrm{min}$. The composition of the gas mixture at the inlet and outlet of the thermal chamber was constantly monitored during the heating. If necessary, nitrogen was used as 


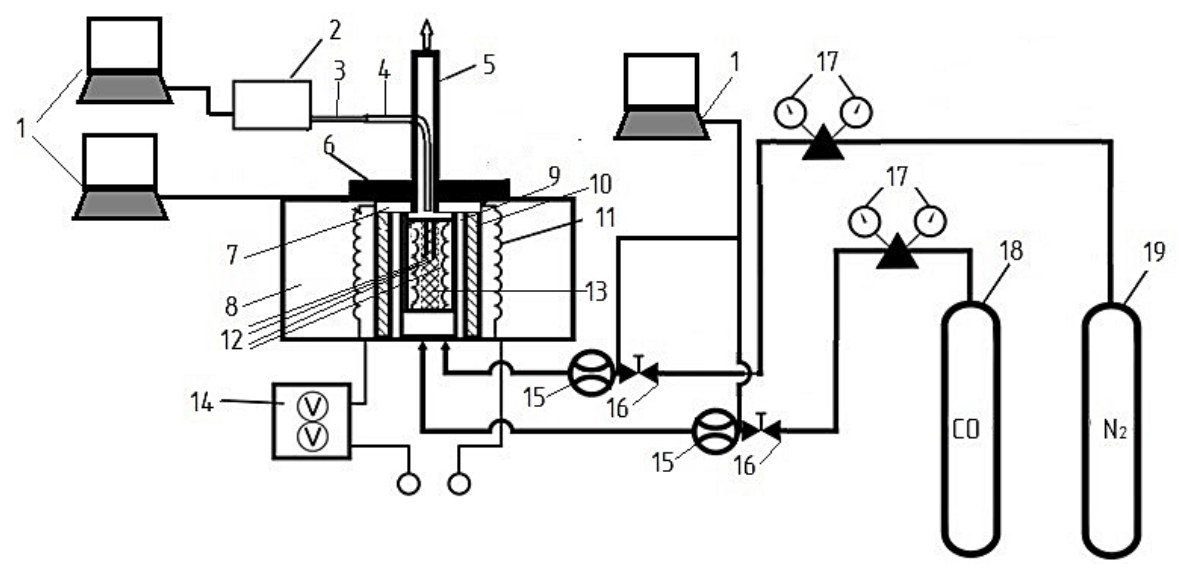

Fig. 1. Experimental setup for the investigation of the catalytic processes of carbon monoxide oxidation: 1 - the digital interface of measurements; 2 -VARIO PLUS gas analyzer, MRU industrial analyzer; 3 - a gas sampler of the gas analyzer; 4 - tube for the sampling of the gas mixture from the chamber to the gas analyzer; 5 - removal of the gas mixture; 6 - metal gasket; 7 - asbestos gasket; 8 - thermal chamber; 9 -stainless steel tube; 10 - ceramic tube; 11 - heating element; 12 - thermocouples; 13 - container for the catalyst made as a grid from stainless steel; 14 - temperature regulator; 15 - Bronkhorst EL-FLOW, F-111AC gas flow meters; 16 -F-001AC control valves; 17 - reducers; 18 - carbon monoxide cylinder; 19 - nitrogen cylinder

the inert gas. The concentration of the reaction products was analyzed using a VARIO PLUS industrial analyzer MRU air fair, with an accuracy $\pm 20 \mathrm{ppm}$ or $\pm 5 \%$ of the measurement values. Immediately before the catalytic experiment, the catalyst grain was pre-heated at a temperature $450^{\circ} \mathrm{C}$ for 2 hours. The weight loss of the catalyst was determined both after heating and cooling. Catalytic purification of a gas mixture from $\mathrm{CO}$ was investigated in the temperature range of $200-400^{\circ} \mathrm{C}$. The molar fraction of carbon monoxide in the initial gas mixture at the inlet to the reactor was equal to 1.1 .

The conversion rate of carbon monoxide was calculated as

$$
X_{C O}=\frac{C_{C O}^{i n}-C_{C O}^{o u t}}{C_{C O}^{i n}} \cdot 100 \%
$$

where: $C_{C O}^{i n}$ is the molar fraction of $\mathrm{CO}$ at the reactor inlet, $C_{C O}^{\text {out }}$ is the molar fraction of $\mathrm{CO}$ at the reactor outlet.

The composition of the main elements of samples of unmodified and $\mathrm{MnO}_{2}$-modified zeolite of the Sokyrnytsia deposit without heat treatment and after heat treatment was determined by micro-X-ray spectral analysis of fracture and surface, performed using scanning electron microscopy at PEM-106I (SELMI, Ukraine). This device was also used to visualize the surface topography of the samples of unmodified and $\mathrm{MnO}_{2}$-modified zeolite.
The structural parameters of the samples of unmodified and $\mathrm{MnO}_{2}$-modified zeolite (without heat treatment and after heat treatment at $450^{\circ} \mathrm{C}$ for $2 \mathrm{~h}$ ) were determined with low-temperature nitrogen adsorption/desorption methods. The samples were ground to obtain a grain size of $0.5-1 \mathrm{~mm}$, washed with distilled water and air dried at room temperature $\left(25^{\circ} \mathrm{C}\right.$, relative humidity $45 \%$ ). The samples were prepared by degassing them with nitrogen at $150^{\circ} \mathrm{C}$ for 6 hours. The specific surface area $(\mathrm{S})$, total pore volume $\left(\mathrm{V}_{\Sigma}\right)$ and pore size distribution were calculated using adsorption data obtained using Nova Quntachrome $4200 \mathrm{e}$ sorbometer (USA) at $-196^{\circ} \mathrm{C}$. The specific surface area (S) was calculated using the Brunauer-Emmett-Teller (BET) method. The total pore volume $\left(\mathrm{V}_{\Sigma}\right)$ was estimated by converting the volume of nitrogen adsorbed at $\mathrm{p} / \mathrm{p}_{0} \approx 0.98$ to the volume of liquid adsorbate. The pore size distribution was calculated by the Barrett-JoynerHalenda (BJH) and DFT (Density functional theory) methods, using the electron density of the framework oxygen.

The phase composition of the samples of unmodified and $\mathrm{MnO}_{2}$-modified zeolite (without heat treatment and after heat treatment at $450^{\circ} \mathrm{C}$ for $2 \mathrm{~h}$ ) was determined by XRD using diffractometer DRON-2 with two Soller slits with filtered Co-K $\alpha$ rays. The phase composition of the powder sample of the $\mathrm{MnO}_{2}$-catalyst, air-dried to constant weight, was determined by XRD using Ultima IV diffractometer (Rigaku, Japan) with 
$\mathrm{Cu}-\mathrm{K} \alpha$ rays and a graphite monochromator. The mineral-phase identification of the studied samples was performed by comparing the obtained diffraction lines with reference XRD pattern of minerals and their synthetic analogs, provided in the ASTM radiographic file, the base of crystal structures of the American Mineralogical Society and the D. Bartel public mineralogical base of minerals. The quantitative content of the identified minerals was measured by comparing and extrapolating the intensities from several XRD patterns obtained for the samples with the addition of known fixed amounts of pure minerals (in our case it was quartz) by the method of additives.

\section{RESULTS AND DISCUSSION}

The investigation of $\mathrm{CO}$ oxidation in the gas mixture in an empty reactor showed that in the entire temperature range $\left(200-400^{\circ} \mathrm{C}\right)$ the degree of carbon monoxide conversion in the absence of a catalyst was equal to 0 . The mass loss of catalysts during heat treatment was $8-10 \%$, which does not contradict the data on the water content in the zeolite of the Sokyrnytsia deposit [Vasylechko et al., 2016; Grechanovskaya, 2010; Geviuk, 2015]. Fig. 2 shows that $100 \%$ conversion of carbon monoxide was achieved at $390^{\circ} \mathrm{C}$ in the case of Gp70. In the case of using the manganeseoxide catalyst, the CO conversion was $92.8 \%$. The carbon monoxide conversion on Gp60 and the chromium-ferrite catalyst was $85.3 \%$ and $82.4 \%$, respectively. The use of copper-ferrite, ferrite, and chromium-oxide catalyst provided $41.2 \%, 48.5 \%$, and $55.9 \% \mathrm{CO}$ oxidation, respectively, at $390^{\circ} \mathrm{C}$.

The data presented in Figure 2 indicate that the zeolite-manganese oxide catalyst shows the best performance. Its multi-functionality in terms of environmentally sound catalysis is provided by the possibility to obtain the catalyst without the pre-treatment of zeolite, perhaps even from spent sorbents for purification of manganese-containing natural water [Tarasevich et al., 2012], which can be found in Ukraine. Moreover, in the case of landfilling or storage, it is non-toxic, because the catalyst components are of natural origin. Therefore, our further study was performed for the zeolite-manganese oxide catalyst. Figure 3 gives the micro-X-ray spectral analysis of fracture and surface of samples of unmodified and $\mathrm{MnO}_{2}-$ modified zeolite without heat treatment and after heat treatment.

Figures $3 \mathrm{a}$ and $3 \mathrm{~b}$ illustrate the absence of manganese in the structure and on the surface of the zeolite, whereas Figures 3c, 3d, 3e, and $3 \mathrm{f}$ show its presence in the samples after modification. The increased manganese content on the surface of the $\mathrm{MnO}_{2}$-modified zeolite without heat treatment (Fig. 3d) and after heat treatment (Fig. 3f) indicates the generation of the manganese oxide layer on the zeolite surface with its slightly lower content in the catalyst channels

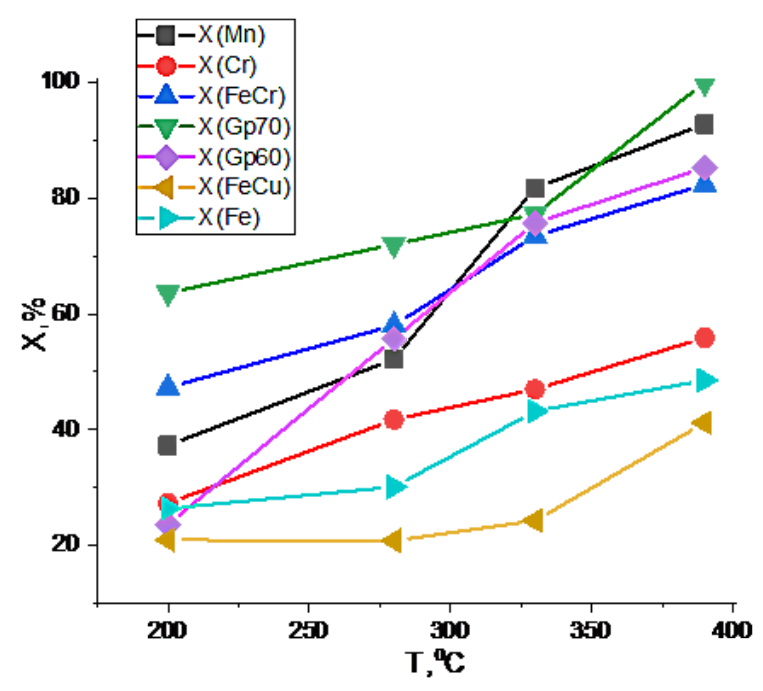

Fig. 2. Temperature dependence of the carbon monoxide conversion over the zeolite-based catalysts: $\mathrm{Mn}$ - manganese oxide, $\mathrm{Cr}$ - chromium oxide catalyst, $\mathrm{FeCr}$ - chromium-ferrite catalyst, Gp70 - copper-manganese-oxide $\left(30 \% \mathrm{CuO}+70 \% \mathrm{MnO}_{2}\right)$ catalyst, Gp60 - copper-manganeseoxide $\left(40 \% \mathrm{CuO}+60 \% \mathrm{MnO}_{2}\right)$ catalyst, $\mathrm{FeCu}$ - copper-ferrite catalyst, $\mathrm{Fe}$ - ferrite catalyst 
a)

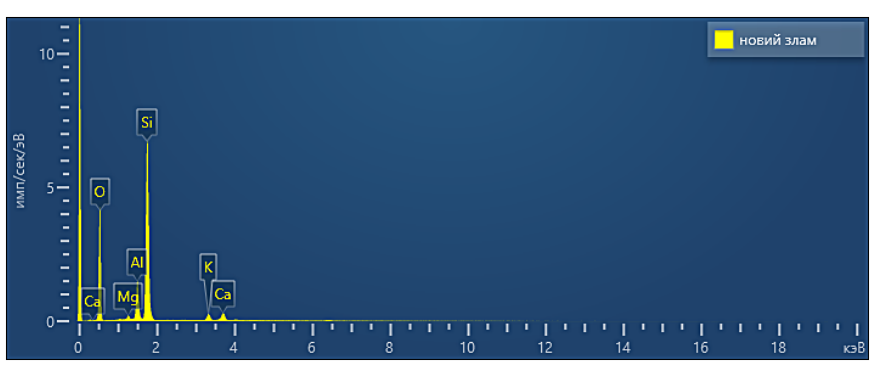

b)

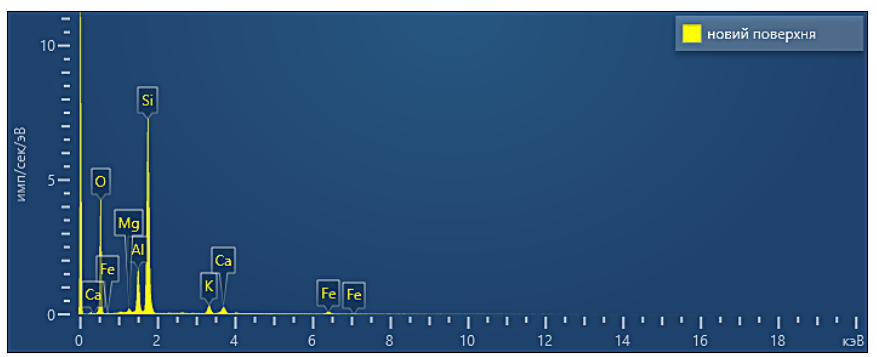

c)

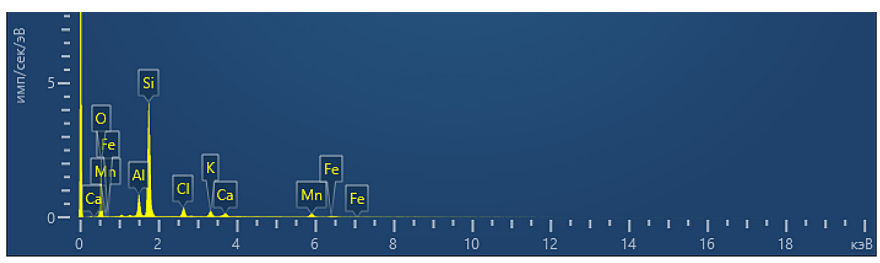

d)

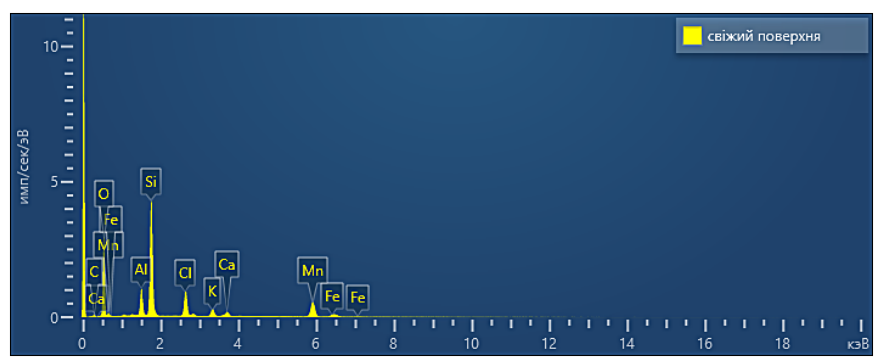

e)

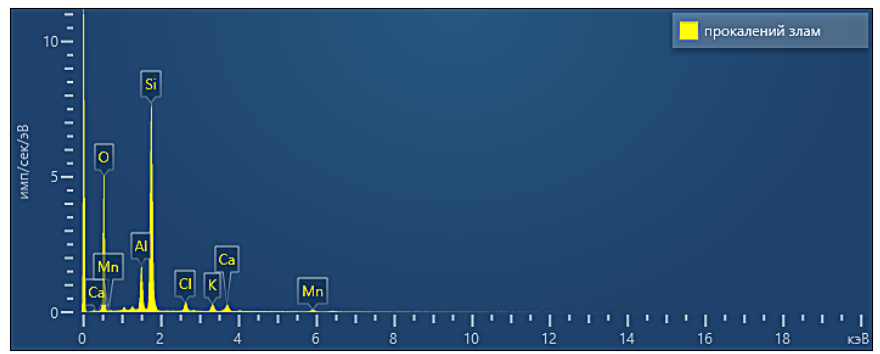

f)

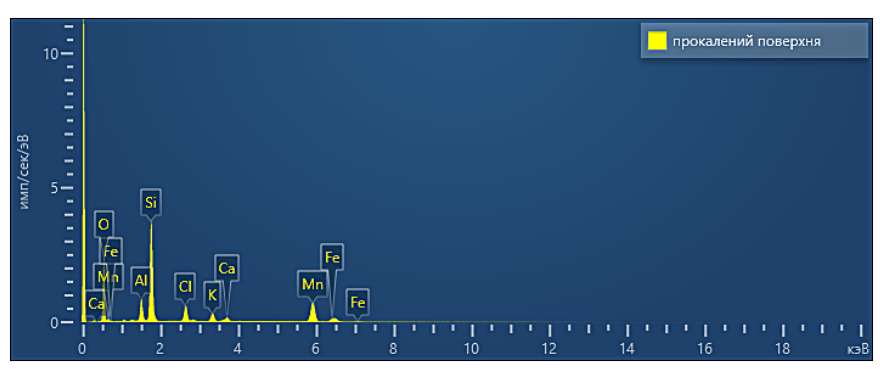

Fig. 3. The micro-X-ray spectrum of zeolite fracture (a) and zeolite surface (b), of the fracture (c, e) and the surface ( $\mathrm{d}, \mathrm{f})$ of the $\mathrm{MnO}_{2}$ - modified zeolite without heat treatment $(c, d)$ and after heat treatment $(e, f)$ 
(Fig. 3c, 3e). It can be confirmed also by the corresponding presence of chlorine, which is one of the components of $\mathrm{MnCl}_{2}$, used to obtain the manganese-oxide catalyst and was not completely removed from the zeolite material in the washing process. The obtained results should be considered more likely as qualitative. However, it should be noted that the mass ratio of $\mathrm{Si} / \mathrm{Al}$ in the studied samples of zeolite at the fracture and the surface is 4.79 and 4.61 , respectively, which correlates well with the data [Malovanyy et al., 2010; Grechanovskaya, 2010] and corresponds to the $\mathrm{Si} / \mathrm{Al}$ ratio for clinoptilolite.

The morphology and surface structure presented by the SEM-image of the samples of unmodified (Fig. 4a) and $\mathrm{MnO}_{2}$-modified zeolite without heat treatment (Fig. 4b) reveal an increased number of surface defects as a result of the hydrated $\mathrm{MnO}_{2}$ amorphous mass formation. As a result of the heat treatment of the $\mathrm{MnO}_{2}$ modified zeolite (Fig. 4c), numerous sintering and crystallization fields with inhomogeneous local manganese-oxide centers of different morphology are observed that visually corresponds to the crystallographic forms of the layered type, probably ramsdellite $\gamma-\mathrm{MnO}_{2}$ [Liu et al., 2013; Chen et al., 2009].

Figure 5 illustrates that the sorption isotherms obtained for the samples of $\mathrm{MnO}_{2}$-modified zeolite without heat treatment, $\mathrm{MnO}_{2}$-modified zeolite after heat treatment $\left(450^{\circ} \mathrm{C}\right.$ for 2 hours $)$ and zeolite without heat treatment do not belong to any type. These isotherms can be attributed to $\mathrm{V}$ type, which is a characteristic of typical microporous materials. At the pressure close to that of saturated vapor, there is no inflection of the isotherm, which is attributed to adsorption in large mesopores and macropores [Greg S. et al., 1983]. There is a decrease in the specific surface area of the zeolite from 219 to $210 \mathrm{~m}^{2} / \mathrm{g}$ after modification of the zeolite with $\mathrm{MnO}_{2}$, which can be explained by the formation of hydrated $\mathrm{MnO}_{2}$ on the surface of zeolite (Table 1). The incorporation of potassium ions from potassium permanganate

b)

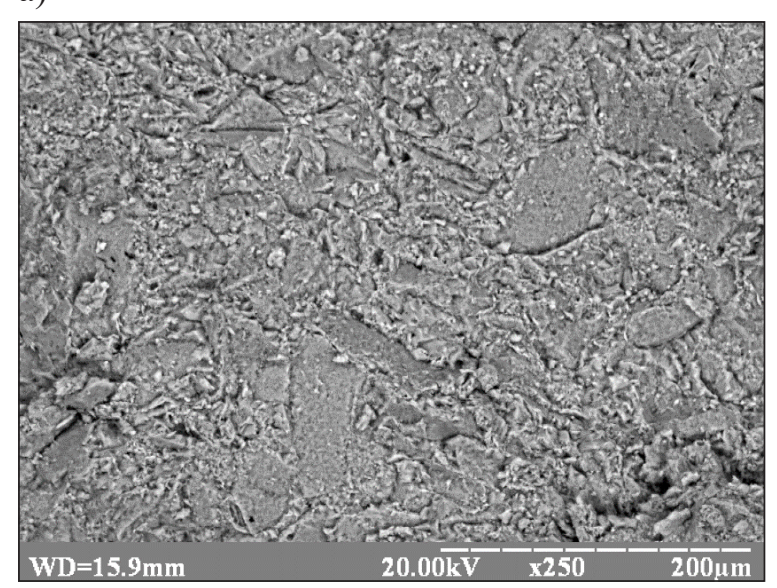

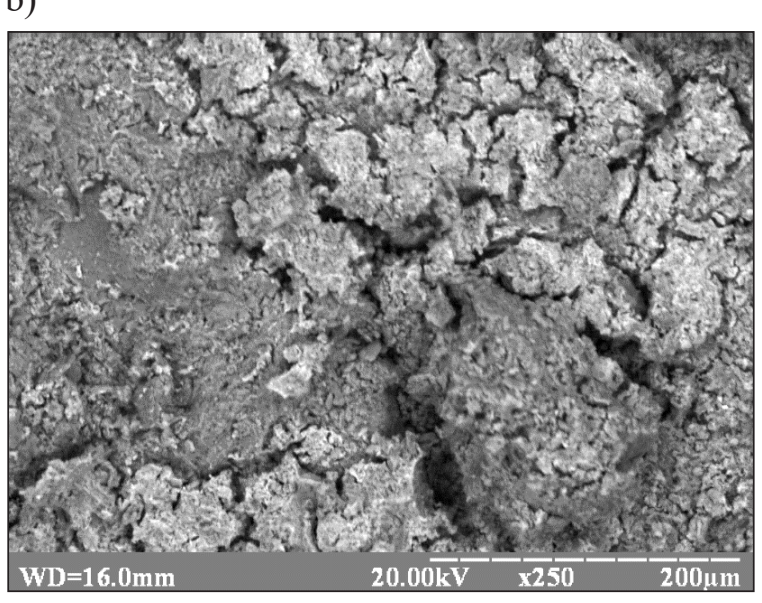

c)

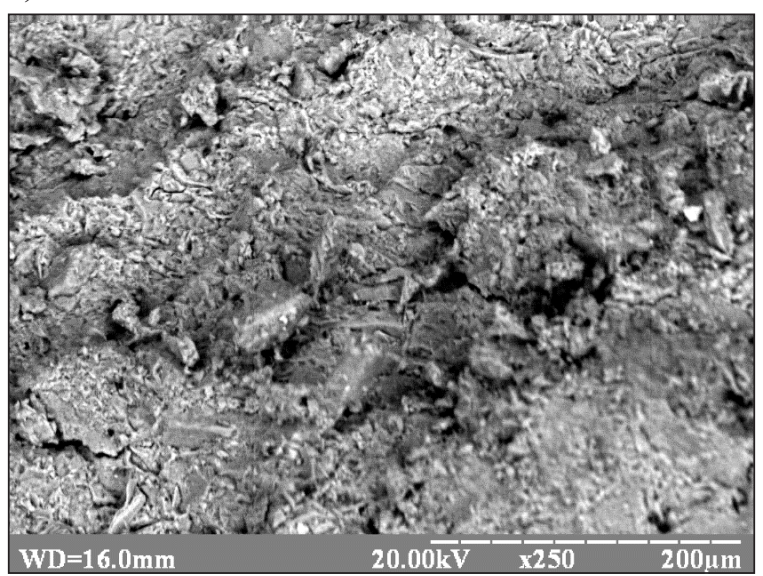

Fig. 4. SEM image of the unmodified zeolite sample (a), the $\mathrm{MnO}_{2}$-modified zeolite sample without heat treatment (b), and after heat treatment (c) 


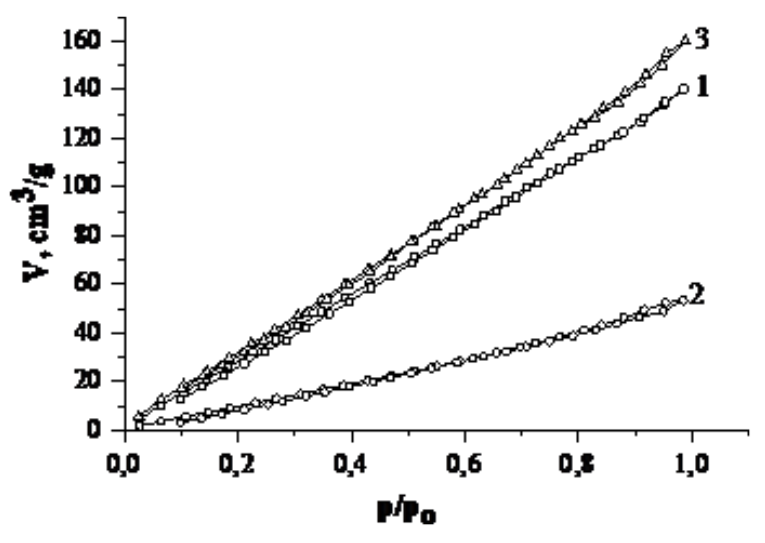

Fig. 5. The nitrogen adsorption and desorption isotherms for the $\mathrm{MnO}_{2}$-modified zeolite without heat treatment (1), $\mathrm{MnO}_{2}$-modified zeolite after heat treatment ( $450{ }^{\circ} \mathrm{C}$ for 2 hours) (2) and zeolite without heat treatment (3)

used to obtain the manganese-oxide catalyst, into the zeolite channels due to their high selectivity and large size also leads to a decrease in the specific surface area. After heat treatment, the specific surface area of the $\mathrm{MnO}_{2}$-modified zeolite is also reduced as much as almost 3 times due to the removal of the carcass-forming water molecules and the corresponding collapse of the zeolite channels. A significant part of the inner surface of clinoptilolite becomes inaccessible for the adsorption of nitrogen molecules as a result of irreversible crystalline destruction [Doebelin et al., 2003]. Moreover, phase transition of hydrated $\mathrm{MnO}_{2}$ and, correspondingly, the enlargement of the zeolite microcrystalline structure take place due to the water loss. The selected methods and calculation models for the estimation of the pores radius give slightly overstated results compared to the known confirmed dimensions of the clinoptilolite channels: A - 7.05 $\times 4.25 \AA, \mathrm{B}-4.60 \times 3.95$ $\AA, \mathrm{C}-5.4 \times 3.9 \AA$ and $5.2 \times 3.9 \AA$ [Merkle et al., 1968] due to the specific geometry of the intersections of the two-dimensional system of zeolite channels and the specific structure of nitrogen molecules.

The XRD patterns presented in Fig. 6a, 6b, 6c show that clinoptilolite is the main rock-forming mineral of the studied solids, its content in the original tuff is $\sim 94 \pm 1 \%$. The largest admixture in the zeolite rock is quartz, it amounts $\sim 5 \pm 1 \%$. The total contribution of other admixtures constitutes $\leq 1 \%$. It should be noted that the sample of zeolite-clinoptilolite, taken for investigations, has fairly high purity, and the phase composition is close to the pure mineral, which is not very common for the zeolites of natural origin. It should also be noted that due to the low content of manganese dioxide in the modified samples (about $1 \%$ ), as well as the overlapping of the most diffraction reflections of the manganese oxide phases on clinoptilolite reflexes, it is not possible to clearly determine the phase state of the modifying substance with the method of qualitative X-ray phase analysis without additional enrichment. The appearance of a small peak $\left(4.04 \mathrm{~A}^{\circ}\right)$ which is a characteristic of $\gamma-\mathrm{MnO}_{2}$ ramsdellite can be observed only for the heat-treated modified sample. However, there is an increase in the amplitude of the background of the diffraction pattern for the modified samples from $40 \mathrm{imp} / \mathrm{s}$ (natural clinoptilolite) to $75 \mathrm{imp} / \mathrm{s}$, which indirectly indicates the deposition of the Mn-containing compounds on the surface of clinoptilolite.

Using a diffraction pattern of the $\mathrm{MnO}_{2}$-catalyst powder, the phases of octahedral molecular sieves of $\beta-\mathrm{MnO}_{2}$ pyrolusite in the amount of $6 \%$, ramsdellite $\gamma-\mathrm{MnO}_{2}-51 \%$, and achtenskite $\varepsilon-\mathrm{MnO}_{2}-43 \%$ are determined (Fig. 7). It confirms the data reported in the literature [Rakitskaya et al. 2017] that the content of these phases is almost the same if the manganese-oxide catalyst is synthesized by means of a similar method. The use of manganese dioxide as a catalyst with the structures of pyrolusite, ramsdellite, or achtenskite is

Table 1. Structural parameters of samples of $\mathrm{MnO}_{2}$-modified and unmodified (after heat treatment and without heat treatment) zeolite

\begin{tabular}{|c|c|c|c|c|c|}
\hline \multirow{3}{*}{ No. } & \multirow{3}{*}{ Sample } & \multirow{3}{*}{$\begin{array}{l}\mathrm{S}, \mathrm{m}^{2} / \mathrm{g}(\mathrm{BET} \\
\text { method) }\end{array}$} & \multirow{3}{*}{$\mathrm{V}_{\Sigma}, \mathrm{cm}^{3} / \mathrm{g}$} & \multicolumn{2}{|c|}{ Distribution of pores by size, $\mathrm{nm}$} \\
\hline & & & & BJH method dV (log r) & DFT method dV (r) \\
\hline & & & & $r_{1}$ & $r_{1}$ \\
\hline 1. & $\begin{array}{l}\mathrm{MnO}_{2} \text {-modified zeolite without heat } \\
\text { treatment }\end{array}$ & 210 & 0.198 & 1.54 & 1.58 \\
\hline 2. & $\begin{array}{l}\mathrm{MnO}_{2} \text {-modified zeolite after heat } \\
\text { treatment }\left(450^{\circ} \mathrm{C} \text { for } 2 \text { hours) }\right.\end{array}$ & 71 & 0.077 & 1.52 & 1.58 \\
\hline 3. & Zeolite without heat treatment & 219 & 0.227 & 1.53 & 1.58 \\
\hline
\end{tabular}




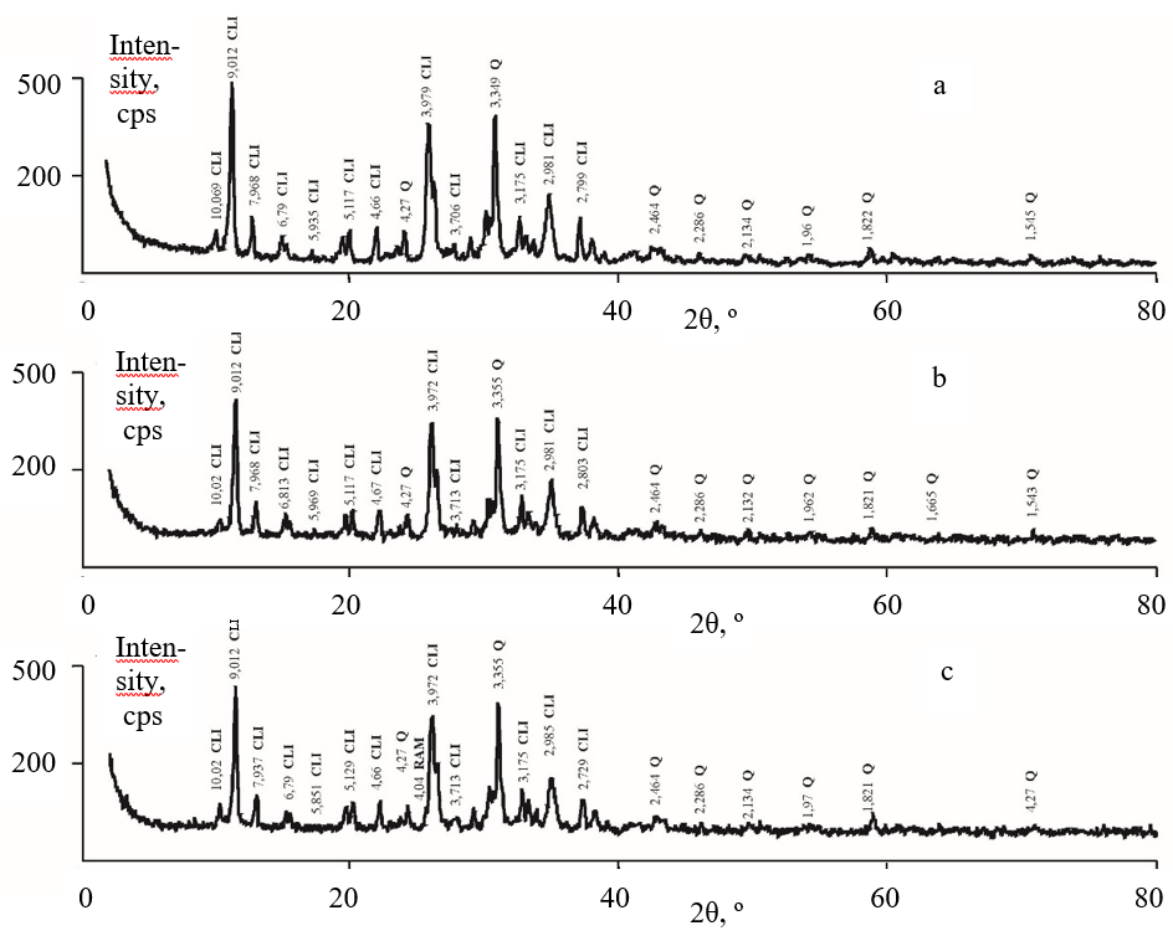

Fig. 6. The results of mineral-phase identification of samples: natural zeolite (a), $\mathrm{MnO}_{2}$-modified zeolite without heat treatment (b), and $\mathrm{MnO}_{2}$-modified zeolite after heat treatment (c)

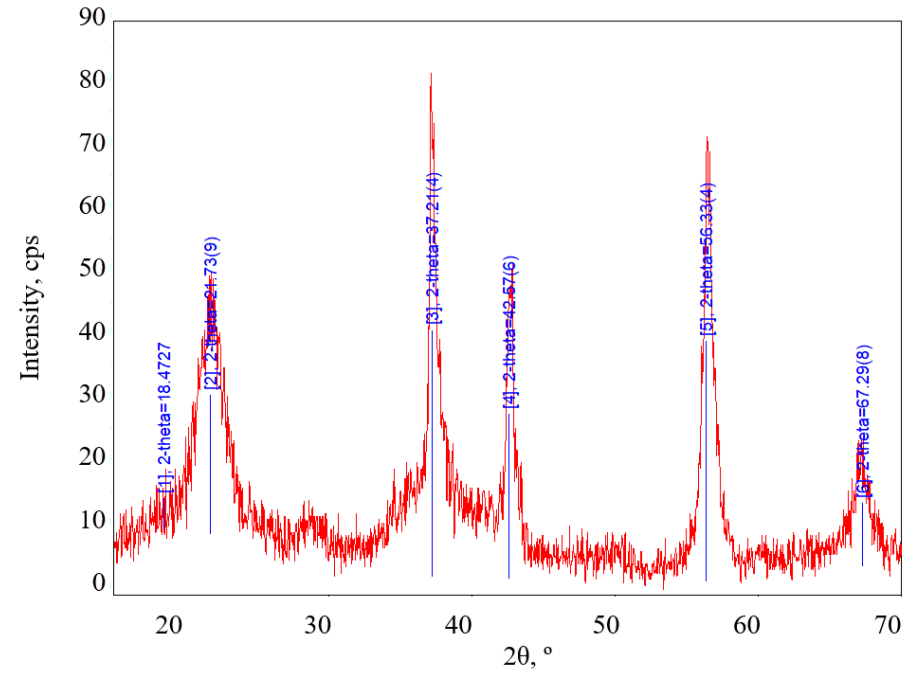

Fig. 7. XRD of $\mathrm{MnO}_{2}$-catalyst powder: 18.4727; 21.73(9) - ramsdellite, 37.21(4); 42.57(6); 56.33(4); $67.29(8)$ - akhtenskit, ramsdellite, pyrolusite

driven by the fact that they are the modifications of $\mathrm{MnO}_{2}$. They consist of rutile-like chains of $\mathrm{MnO}_{6}$-octahedra having two edges in common with neighboring octahedra. The chains are single for pyrolusite, and they are doubled for ramsdellite and achtenskite. The chains contain only the $\mathrm{Mn}^{4+}$ cations. This fact confirms the resistance of the catalyst to poisoning because its effectiveness is specified by the catalytic action of $\mathrm{Mn}^{4+}$ according to the reactions:

$$
\begin{gathered}
\mathrm{CO}+\mathrm{MnO}_{2} \rightarrow \mathrm{CO}_{2}+\mathrm{MnO}, \\
\mathrm{MnO}+\mathrm{O}_{2} \rightarrow \mathrm{MnO}_{2} .
\end{gathered}
$$

It is known that in the Riedhammer multichamber furnaces (Fig. 8) [Riedhammer, 2006] for baking of electrode blanks at "Ukrainian Graphite" PJSC, the flue gas moves from the previous hot to the subsequent colder baking chamber. The maximum increase of carbon 


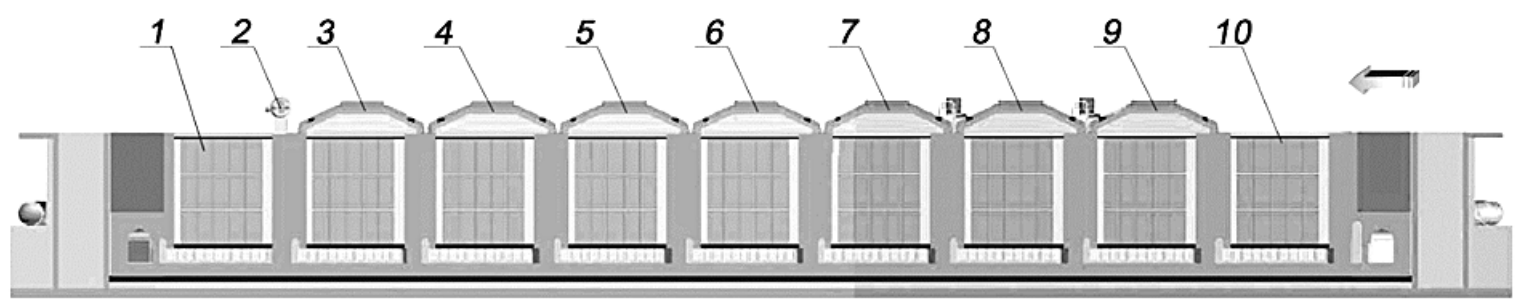

Fig. 8. Scheme of a multi-chamber furnace of the Riedhammer type: 1 - the chamber on loading; 2 - equipment for flue gas removal; 3-6 - chambers heated by flue gases of chambers 7, 8; 7, 8- cameras "under fire"; 9 chamber on cooling; 10 - camera on unloading

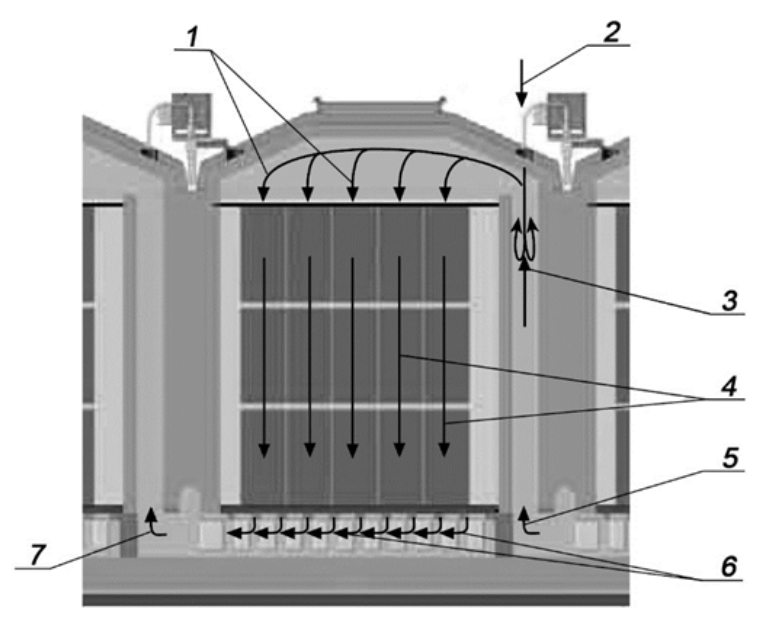

Fig. 9. Scheme of gases movement in the baking chamber: 1 - hot flue gases under the vault, 2 - influent gaseous fuel, 3 - combustion of gases in the fire channels, 4 - hot flue gases in the muffle channels, 5, 7 - heated air and flue gases respectively, 6 - the movement of flue gases under the bottom

monoxide concentration in the flue gases occurs at $300-400^{\circ} \mathrm{C}$, which corresponds to the temperatures of the chambers heated by the flue gases [Karvatskii et al., 2011; Ivanenko et al., 2020].

Figure 9 illustrates an innovative technical solution to the problem of flue gas purification from carbon monoxide in multi-chamber furnaces for baking of electrode blanks. It is based on the placement of containers with a catalyst in the fire channels of the chambers heated by flue gases with an appropriate temperature. Containers should have rectangular cross-section to prevent the passing the gas mixture by the catalyst (Fig. 10).

In order to test the developed flue gas cleaning catalyst, a pilot 4 tons batch of the catalyst was prepared. The catalyst was placed into two identical containers, each $1 \mathrm{~m}$ long, that were placed sequentially in channel 7 (Fig. 9) of the heated air and flue gases outlet. The test results showed a stable operation of the catalyst for 440 hours. Table 2 gives the composition of the exhaust gas with and without catalytic treatment. The use of the developed catalyst for furnace gas treatment reduces the carbon monoxide content below the standard maximum permissible emission of $0.25 \mathrm{~g} / \mathrm{m}^{3}$.

The requirements of the regulations on the carbon monoxide emissions from flue gases were

Table 2. The gas composition with and without the catalyst

\begin{tabular}{|l|c|c|}
\hline \multirow{2}{*}{ Component } & \multicolumn{2}{|c|}{ Concentration, $\mathrm{g} / \mathrm{m}^{3}$} \\
\cline { 2 - 3 } & $\begin{array}{c}\text { without the } \\
\text { catalyst }\end{array}$ & with the catalyst \\
\hline $\mathrm{CO}$ & 1.62 & 0.2 \\
\hline $\mathrm{O}_{2}$ & 729 & 728 \\
\hline $\mathrm{CO}_{2}$ & 206 & 208 \\
\hline Other gases & 1022 & 1022 \\
\hline
\end{tabular}

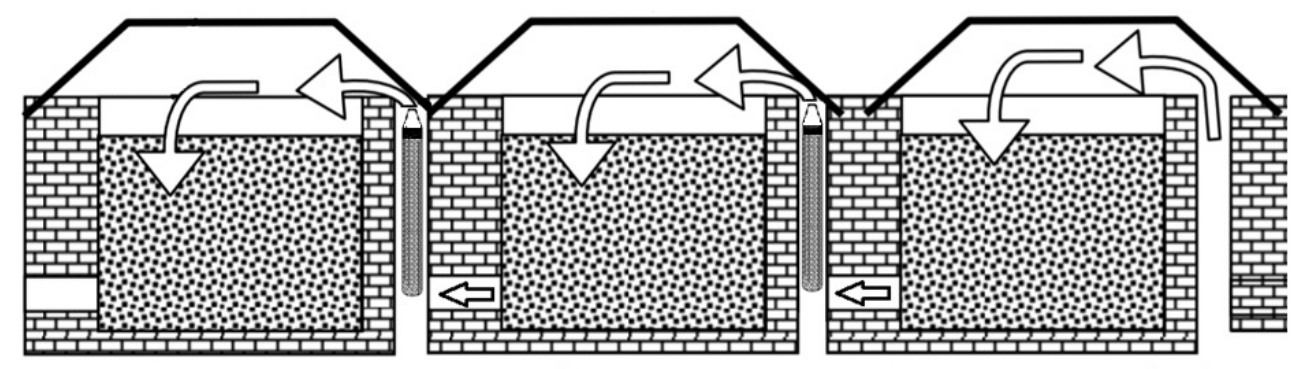

Fig. 10. Layout of containers with catalyst in a multi-chamber baking furnace of the Riedhammer type 
met after the implementation of the developed technical solution for the use of manganese-oxide catalyst based on zeolite [The Standards of Maximum Permissible Emissions of Polluting Substances from Stationary Sources, 2006]. It ensured a successful solution to the problem of exceeding the carbon monoxide emissions standard in the electrode production technology.

\section{CONCLUSIONS}

The presented study gives the development of the manganese-oxide catalyst based on the natural zeolite-clinoptilolite of the Sokyrnytsia deposit for the treatment of flue gas to eliminate carbon monoxide in multi-chamber furnaces. The catalyst is characterized by cheapness, availability, the prevalence in Ukraine, high performance, and environmental safety. According to the results of micro-X-ray spectral analysis of fracture and surface of unmodified and $\mathrm{MnO}_{2}$-modified zeolite samples, the presence of manganese in the structure and surface of zeolite after modification and its absence in the samples of natural zeolite were shown. The SEM images revealed an increase in surface defects as a result of the formation of an amorphous mass of hydrated $\mathrm{MnO}_{2}$ on the surface of the $\mathrm{MnO}_{2}$-modified zeolite sample without heat treatment compared to the unmodified sample. In the case of the heat treatment of the $\mathrm{MnO}_{2}$-modified zeolite, numerous sintering and crystallization fields with inhomogeneous local manganese-oxide centers of different morphology were recorded, which visually correspond to the crystallographic forms of the layered type of ramsdellite $\gamma-\mathrm{MnO}_{2}$.

A decrease in the specific surface area of the $\mathrm{MnO}_{2}$-modified zeolite without heat treatment was found. It indicates the formation of hydrated $\mathrm{MnO}_{2}$ on the zeolite surface. It was determined that the specific surface area of the $\mathrm{MnO}_{2}$-modified zeolite after heat treatment decreases almost 3 times due to the removal of the carcass-forming water molecules. Therefore, a significant part of the inner surface of clinoptilolite became unavailable for the adsorption of nitrogen molecules. According to the results of the qualitative X-ray phase analysis of the unmodified and $\mathrm{MnO}_{2}$-modified zeolite samples, it was shown that the main rock-forming mineral of experimental samples was clinoptilolite, its content constituted $\sim 94 \pm$ $1 \%$, and the largest admixture in zeolite rock was quartz $\sim 5 \pm 1 \%$. For the heat-treated modified sample, the appearance of the peak characteristic for $\gamma-\mathrm{MnO}_{2}$ ramsdellite was determined. According to the results of the qualitative $\mathrm{X}$-ray phase analysis, the presence of the ramsdellite $\gamma-\mathrm{MnO}_{2}$ phase in the amount of 51\% was determined in a sample of $\mathrm{MnO}_{2}$-catalyst powder surface, which confirmed the research results.

The CO conversion of $92.8 \%$ was achieved for the manganese-oxide catalyst. The requirements of carbon monoxide emissions standard for flue gases will be met after the implementation of the developed catalyst in the production. The developed catalyst is proposed to be placed in the containers in the fire channels of chambers heated by flue gases, multi-chamber furnaces for baking of electrode blanks, which is an innovative technical solution to the problem of purification of flue gases from carbon monoxide. The environmental safety of $\mathrm{MnO}_{2}$-catalyst for flue gas treatment of electrode production is justified by the synthesis of the catalyst from spent sorbents for purification of manganese-containing natural water and by its non-toxicity in case of disposal or storage on landfills. Our study shows the high performance of the $\mathrm{MnO}_{2}$-modified zeolite for the treatment of flue gas to eliminate carbon monoxide in multi-chamber furnaces.

\section{REFERENCES}

1. Kursov S.V. 2015. Carbon Monoxide: Physiological Importance and Toxicology. Emergency medicine, 6 (69), 9-16. (in Russian).

2. Patel D. M., Kodgire P., Dwivedi A. H. 2019. Low temperature oxidation of carbon monoxide for heat recuperation: A green approach for energy production and a catalytic review. Journal of Cleaner Production, 97.

3. Statistical Yearbook «Environment of Ukraine 2018». 2019. State Statistics Service of Ukraine: Kyiv, 214. (in Ukrainian).

4. Ivanenko O. 2020. Implementation of risk assessment for critical infrastructure protection with the use of risk matrix. ScienceRise, 2, 26-38.

5. Environmental passport of Zaporizhzhia region for 2018. 2019. Official portal of the Ministry of Energy and Environmental Protection of Ukraine, 173. (in Ukrainian).

6. Riedhammer. 2006. Ring Pit Furnaces for Baking of high quality Anodes - an Overview, 15.

7. Panov Ye., Gomelia N., Ivanenko O., Vahin A., Leleka S. 2020. Assessment of the Effect of Oxygen 
and Carbon Dioxide Concentrations on Gas Evolution During Heat Treatment of Thermoanthracite Carbon Material. Journal of Ecological Engineering, 2 (2), 139-149.

8. The Order no. 309 of the Ministry of Ecology and Natural Resources of Ukraine dated June 27, 2006 The Standards of Maximum Permissible Emissions of Polluting Substances from Stationary Sources. (in Ukrainian).

9. Karvackii A. Ya., Leleka S. V., Pulinec I. V., Lazariev T. V. 2011. Development of burning regulations taking into account the dynamics of gas emission of baking blanks. Eastern-European Journal of Enterprise Technologies, 6[5(54)], 42-45. (in Ukrainian).

10. Karvatskii A. Ya., Shylovych I. L., Krutous L. V., Kutuzov S. V. 2013. Decrease of CO concentration using installation for carbon monooxide conversion. Eastern-European Journal of Enterprise Technologies, 2 (11 (62)), 38-41. (in Ukrainian).

11. Belokon K. V., Belokon Y.A., Kozhemyakin G. B., Matukhno E. V.2016. Environmental assessment of the intermetallic catalysts utilization efficiency for deactivation of the pollutants emitted by electrode production enterprises. Naukovyi Visnyk Natsionalnoho Hirnychoho Universytetu, 3, 87-94.

12. Basaraba Y. B., Zasadnyi T. M. 2014. Prospects for the zeolites application of the Sokyrnytsia deposit for natural water purification. Ecological Safety and Balanced Use of Resources, 1(11), 46-52. (in Ukrainian).

13. Zasidko I. B., Polutrenko M. S., Mandryk O. M. 2017. Use of zeolite for cleaning of natural water and effluents of communal enterprises. Scientific Bulletin of UNFU, 27(5), 63-66. (in Ukrainian).

14. Malovanyy M., Yarema O., Sakalova G., Vasylinych T. 2010. Purification of wastewater from tanning industry from chromium ions adsorption on natural zeolites. Bulletin of the Kyiv National University of Technologies and Design, 6, 81-85. (in Ukrainian).

15. Yanovska E. S., Zatovskiy I. V., Slobodyanik N. S. 2008. Scientific bases of waste-free technology of industrial wastewater treatment from mixtures of heavy metal ions. Environmental ecology and life safety, 5, 50-54. (in Ukrainian).

16. Grechanovskaya E. E. 2010. Unit cell metric and Si/ Al ratio in zeolites of the heulandite- clinoptilolite series of the Sokirnytsya deposit (Transcarpathia, Ukraine). Mineralogical Journal, 32(4), 12-22. (in Ukrainian).

17. Korablev V. V., Chechevichkin A.V., Boricheva I. B., Samonin V. V. 2017. The structure and morphological properties of clinoptilolite modified by manganese dioxide. SPbPU Journal - Physics and Mathematics, 10(1), 100-111. (in Russian).

18. Inglezakis V. J., Zorpas A. A. 2012. Handbook of natural zeolites. Bentham Science Publishers, 705.
19. Tarasevich Yu. I., Goncharuk V. V., Polyakov V. E., Krysenko D. A., Ivanova Z. G., Aksenenko E. V., Tryfonova M. Yu. 2012. Efficient technology for the removal of iron and manganese ions from artesian water using clinoptilolite. Journal of Industrial and Engineering Chemistry, 18 (4), 1438-1440.

20. Panov Ye., Gomelia N., Ivanenko O., Vahin A., Leleka S. 2019. Estimation of the effect of temperature, the concentration of oxygen and catalysts on the oxidation of the thermoanthracite carbon material. Eastern-European Journal of Enterprise Technologies, 2/6 (98), 43-50.

21. Choi K.-H., Lee D.-H., Kim H.-S., Yoon Y.-C., Park C.-S., Kim Y. H. 2016. Reaction Characteristics of Precious-Metal-Free Ternary $\mathrm{Mn}-\mathrm{Cu}-\mathrm{M}(\mathrm{M}=\mathrm{Ce}$, $\mathrm{Co}, \mathrm{Cr}$, and $\mathrm{Fe}$ ) Oxide Catalysts for Low-Temperature CO Oxidation. Industrial \& Engineering Chemistry Research, 55(16), 4443-4450.

22. Rakitskaya T. L., Kiose T. A., Vasylechko V. O., Volkova V. Ya., Gryshchouk G. V. 2011. Adsorption-desorption properties of clinoptilolites and the catalytic activity of surface $\mathrm{Cu}$ (II)-Pd(II) complexes in the reaction of carbon monoxide oxidation with oxygen. Chemistry of metals and alloys, 4 (3-4), 213-218.

23. Lou J.C., Chang C.K. 2006. Catalytic oxidation of $\mathrm{CO}$ over a catalyst produced in the ferrite process. Environmental Engineering Science, 23(6), 1024-1032.

24. Radovenchik V. M., Ivanenko O. I., Radovenchik Y. V., Krisenko T. V. 2020. Application of ferrite materials in water purification processes. Monograph: O. V. Pshonkivsky, 215. (in Ukrainian).

25. Golodets G. I. 1983. Heterogeneous Catalytic Reactions Involving Molecular Oxygen. Studies in Surface Science and Catalysis: Elsevier Science Publishers, 15, 878.

26. Panov E. N., Shilovich I. L., Ivanenko E. I., Buryak V. V. 2012. Thermal and chemical aspects of formation co in the process of baking of electrodes. Eastern-European Journal of Enterprise Technologies, 4 (6 (58)), 15-18. (in Ukrainian).

27. Biemelt T., Wegner K., Teichert J., Lohe M. R., Martin J., Grothe J., Kaskel S. 2016. Hopcalite nanoparticle catalysts with high water vapour stability for catalytic oxidation of carbon monoxide. Applied Catalysis B: Environmental. 184. P. 208-215.

28. Mirzaei A. A., Shaterian H. R., Joyner R. W., Stockenhuber M., Taylor S. H., Hutchings G. J. 2003. Ambient temperature carbon monoxide oxidation using copper manganese oxide catalysts: Effect of residual $\mathrm{Na}+$ acting as catalyst poison. Catalysis Communications, 4(1), 7-20.

29. Rakhimova N. R., Rakhimov R. Z. 2007. Stone strength of composite slag-alkaline binders with zeolite-containing additives. Vestnik Tomskogo 
gosudarstvennogo arkhitekturno-stroitel'nogo universiteta. Journal of Construction and Architecture, 2, 191-198. (in Russian).

30. Vatin N. I., Chechevichkin V. N., Chechevichkin A. V., Shilova E. S. 2013. Application of clinoptilolite type zeolites for natural water purification. Magazine of Civil Engineering, 2 (37), 81-88. (in Russian).

31. Tarasevich Yu.I., Kulishenko A.E., Ostapenko R.V., Kravchenko T.B. 2013. Investigation of the process of water demanganation in pilot conditions. Ukrainian chemical journal, 79 (10), 101-106. (in Ukrainian).

32. Mitzi Von David B. 2009. Solution Processing of Inorganic Materials. Angewandte Chemie. 121(30):5503-5503.

33. Doebelin N., Armbruster T. 2003. Stepwise dehydration and change of framework topology in Cdexchanged heulandite. Microporous and Mesoporous Materials, 61, 85-103.

34. Merkle A. B., Slaughter M. 1968. Determination and refinement of the structure of heulandite. The American mineralogist, 53, 1120-1138

35. Vasylechko V., Gryshchouk G., Viter M., Kalychak Ya. 2016. Preconcentration of the Sm(III) on transcarpathian clinoptilolite. Visnyk of the Lviv University. Series Chemistry, 57 (1), 232-241. (in Ukrainian).
36. Geviuk I. N., Kropyvnytska T. P., Sanytsky M. A. 2015. Composite portland cements with the additives of natural zeolite and limestone. Resource-saving materials, structures, buildings and structures, 31, 149-156. (in Ukrainian).

37. Liu X., Chen C., Zhao Y., Jia B. 2013. A review on the synthesis of manganese oxide nanomaterials and their applications on lithium-ion batteries. Journal of Nanomaterials, 2013, ID 736375, 7.

38. Chen S., Zhu J., Han Q., Zheng Z., Yang Y., Wang X. 2009. Shape-Controlled Synthesis of One-Dimensional $\mathrm{MnO} 2$ via a Facile Quick Precipitation Procedure and its Electrochemical Properties. Crystal Growth \& Design, 9(10), 4356-4361.

39. Greg S., Sing K. 1984. Adsorption, Specific Surface, Porosity. Moscow: Mir, 310. (in Russian).

40. Rakitskaya T. L., Truba A. S., Nagaevs'ka A. V. 2017. Synthesis and catalytic activity of dispersed manganese (IV) oxides in the reaction of ozone decomposition. Odesa National University Herald Chemistry, 22(4(64)), 6-14. (in Ukrainian).

41. Ivanenko O., Gomelya N., Panov Ye. 2020. Evaluation of the influence of the catalysts application on the level of emissions of carbon monoxide in the manufacture of electrodes. Technology audit and production reserves, 4/3(54), 4-11. 